\title{
A Diffuse Leptomeningeal Glioneural Tumor Case Producing Hydrocephalus and Polyradiculopathy
}

\section{Relato de um caso de tumor glioneuronal leptomeníngeo difuso produzindo hidrocefalia e polirradiculopatia}

\author{
Helder Picarelli ${ }^{10}$ Thales Bhering Nepomuceno ${ }^{2}$ \\ Eberval Gadelha Figueiredo ${ }^{20}$ (ICESP), São Paulo, SP, Brazil
2 Division of Neurosurgery, Hospital das Clínicas da Faculdade de Medicina da Universidade de São Paulo, São Paulo, SP, Brazil
${ }^{3}$ Division of Anatomical Pathology, Hospital das Clínicas da Faculdade de Medicina da Universidade de São Paulo, São Paulo, SP, Brazil, \\ ${ }^{1}$ Division of Neurosurgery, Instituto do Câncer do Estado de São Paulo \\ Arq Bras Neurocir 2020;39(3):217-221.
}

\author{
Renan Ribeiro Ribeiro ${ }^{3}$ Vitor Nagai Yamaki ${ }^{2}$
}

Address for correspondence Helder Picarelli, MD, Divisão de Neurocirurgia, Instituto do Câncer do Estado de São Paulo (ICESP), Rua Itacolomi, 538, apto 121, Higienópolis, São Paulo, SP, 01239-020, Brazil (e-mail: helder.picarelli@hc.fm.usp.br; hpicarelli@gmail.com).

\section{Abstract}

Keywords

- leptomeningeal glioneuronal tumor

- polyradiculopathy

- hydrocephalus

- oligodendroglial-like leptomeningeal tumor of childhood

- PCV chemotherapy

\section{Resumo}

Palavras-chave

- tumor glioneural leptomeníngeo difuso

- polirradiculopatia

- hidrocefalia

- oligodendroglial-like

- PCV
The present report describes the case of a male 17-year-old patient who progressively developed a hydrocephalus and polyradiculopathy due to involvement of central nervous system (CNS) by a diffuse leptomeningeal glioneuronal tumor (DLGNT). The tumor had partial remission in response to the treatment with radiotherapy plus procarbazine, lomustine, and vincristine (PCV) chemotherapy, and the patient had improvement in function and pain levels. The current knowledge about DLGNT, including its clinical manifestations, imaging findings, histological characteristics, and treatment are revised and discussed in the present paper.

No presente relato de caso descrevemos um paciente do sexo masculino, com 17 anos de idade, que desenvolveu progressivamente hidrocefalia e polirradiculopatia, devido ao envolvimento do sistema nervoso central por um tumor glioneuronal leptomeníngeo difuso (TGNLD). Nesse caso peculiar obtivemos remissão parcial da neoplasia, melhora funcional e controle álgico do paciente após o tratamento com radioterapia e quimioterapia adjuvante com procarbazina, lomustina e vincristina (PCV). O conhecimento atual sobre TGNLD, incluindo suas manifestações clínicas, achados de imagem, características histológicas e tratamento são revisados e discutidos neste artigo.

\section{Introduction}

The diffuse leptomeningeal glioneuronal tumor (DLGNT) is a rare primary central nervous system (CNS) neoplasm, which was recognized as a distinctive entity in 2016 by the World
Health Organization (WHO) classification of CNS tumors. ${ }^{1}$ Usually, its diagnosis, based on clinical-epidemiological aspects, is difficult and challenging because it has no pathognomonic signs, and its clinical presentation and imaging findings may vary widely. Despite this, in most descriptions, received

February 17, 2020

accepted

May 12, 2020
DOI https://doi.org/

10.1055/s-0040-1713918. ISSN 0103-5355.
Copyright ( 2020 by Thieme Revinter

Publicações Ltda, Rio de Janeiro, Brazil
License terms

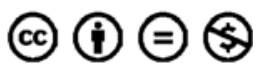




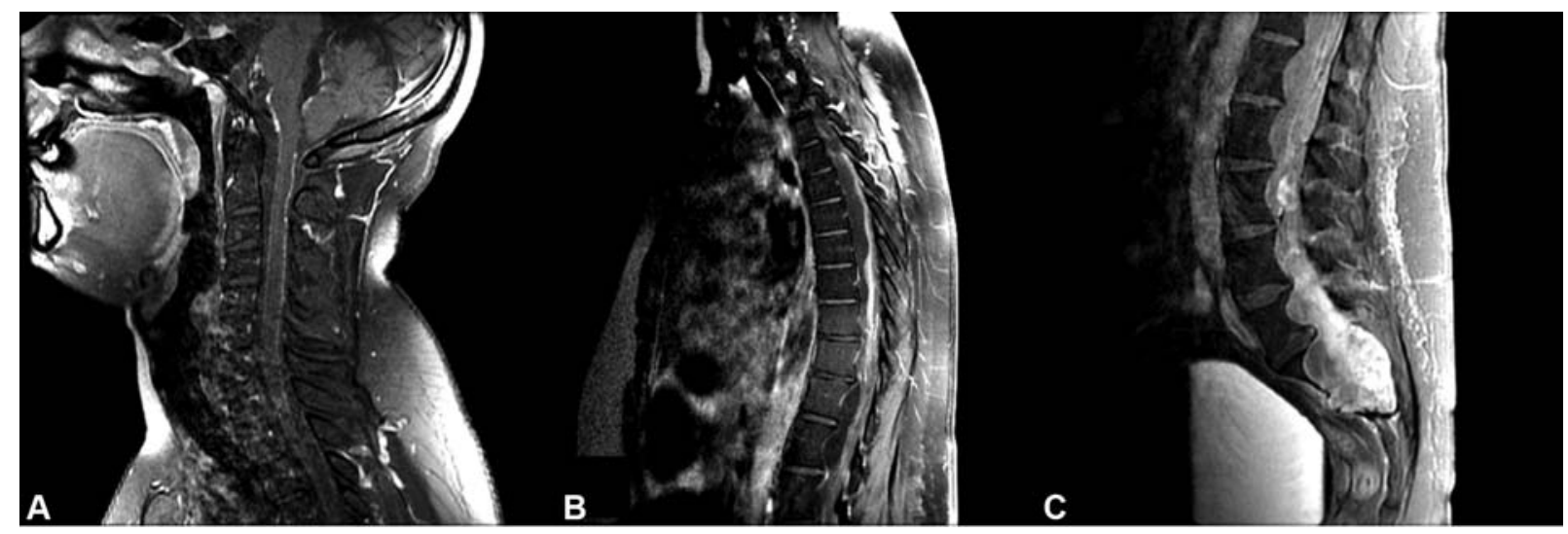

Fig. 1 T1-weighted magnetic resonance imaging with gadolinium. Diffuse leptomeningeal enhancement to the gadolinium injection in the (A) basal cisterns, $4^{\text {th }}$ ventricle, and cervical spinal cord, (B) thoracic spinal cord, and (C) lumbar spinal cord, and cauda equina.

it was more prevalent at a young age, showed slow-growing rate, and imaging exams revealed communicating hydrocephalus with intense leptomeningeal enhancement on T1weigheted images, more frequently in the basal cisterns. Nevertheless, its genetic and epigenetic changes and its exact biological behavior are not yet fully known. ${ }^{2,3}$ We described a late diagnosis of DLGNT in a patient that progressively developed hydrocephalus and polyradiculopathy. Clinical manifestations, imaging and histological characteristics are reported and discussed in the present paper to add evidence and advance current knowledge about the DLGNT.

\section{Case Report}

A 17-year-old male patient sought medical attention at a hospital a few years ago complaining of low back pain, motor incoordination, dizziness, gait disturbance, urinary incontinence, blurred vision, headache, and episodic epileptic seizures, which all had gotten worse progressively in the last months. On his brain computed tomography (CT), a hydrocephalus was diagnosed, which required a ventriculoperitoneal shunt. Due to relief of most of the symptoms, the patient abandoned the follow-up and investigation workup, though the etiology of the hydrocephalus was not accomplished. The patient sought medical attention in our service due to back pain, weakness, and muscle atrophy in the lower limbs, urinary and fecal incontinence, paresthesia and hypoesthesia in different regions of the body. The brain and spine magnetic resonance imaging (MRI) showed a diffuse contrast enhancement on T1weighted images in addition to multiple infiltrative nodular and cystic lesions in the cranial and spinal subarachnoid space, especially in the basal cisterns, brain ventricles, and in the cauda equina (-Fig. 1, 2). A biopsy of a lesion in the cauda equina was performed, and the diagnosis of diffuse leptomeningeal glioneuronal tumor was confirmed (-Figs. 3, -Table 1). At this time, a palliative treatment was proposed, and, a month later, he started to receive three-dimensional conformal radiotherapy to the craniospinal axis (36 Gy in 20 fractions over 4 weeks) with a boost to the sacral tumor (18 Gy in 10 fractions over 2 weeks), adding up to a total dose of $54 \mathrm{~Gy}$. After that, he underwent 3 courses of conventional procarbazine, lomustine, and vincristine (PCV) chemotherapy over 14 weeks, without any complications. Despite partial response to the treatment (-Fig. 4), the patient had improvement in pain levels, function, and quality of life. Although he is still incontinent and unable to walk without assistance, we

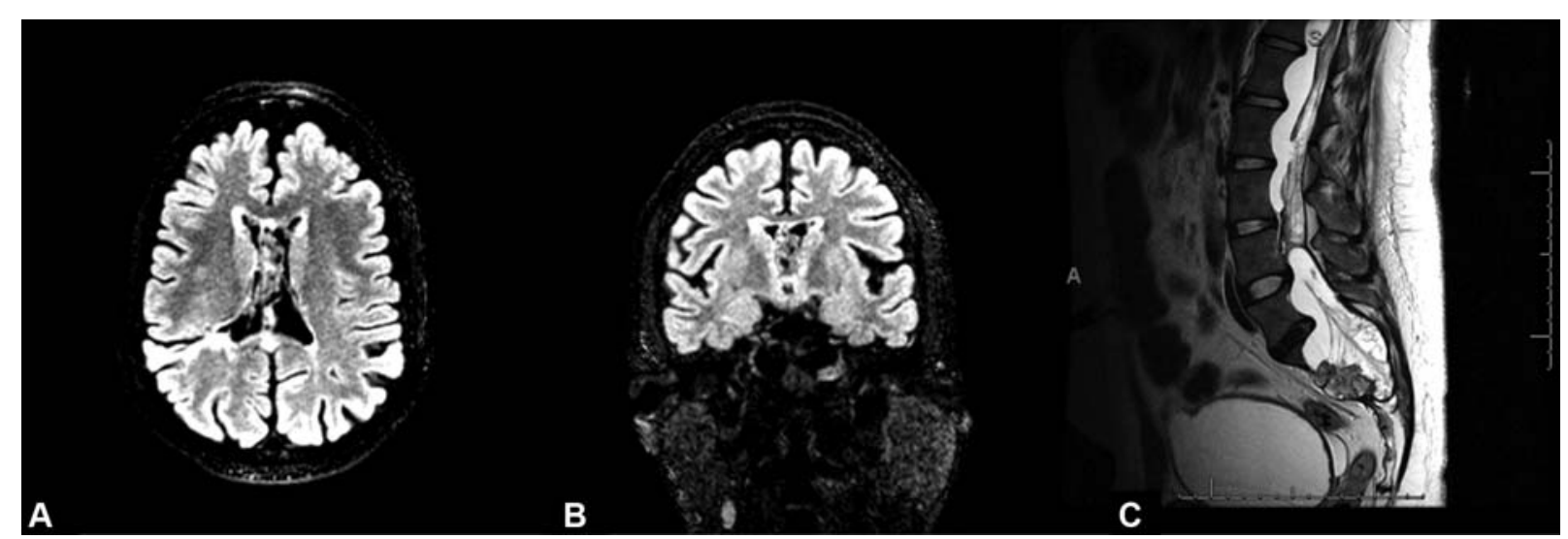

Fig. 2 T2-weighted and fluid attenuated inversion recovery magnetic resonance imaging. Hyperintense subpial nodules and cysts in the (A) septum pelucidum, lateral ventricles, and $3^{\text {rd }}$ ventricle, (B) thoracic spinal cord, and (C) lumbar spinal cord, and cauda equina. 


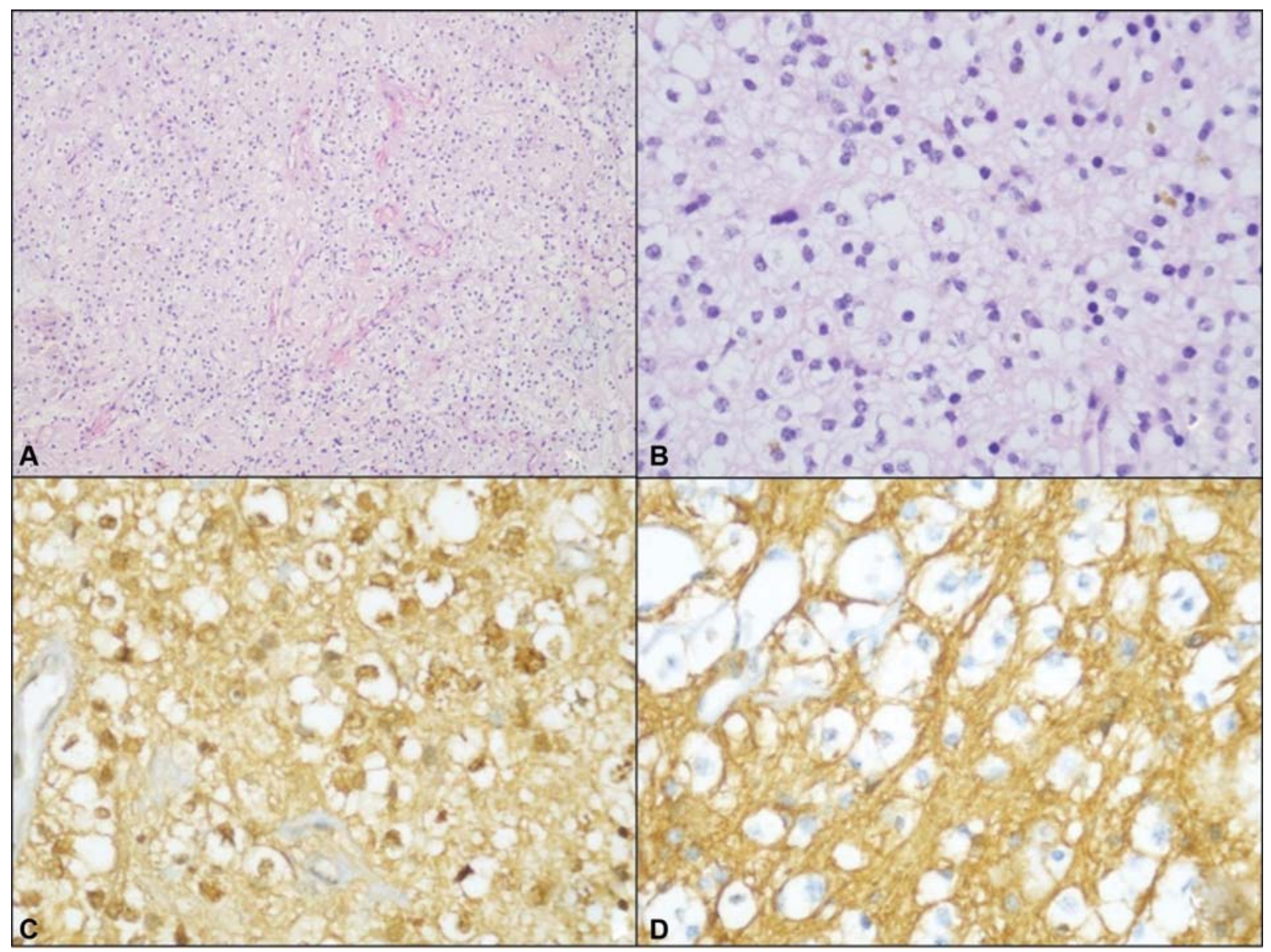

Fig. 3 Histopathological and immunohistochemical study. (A) low power examination reveals a diffuse leptomeningeal proliferation of tumor cells with clear cytoplasm; (B) at higher magnification, the nuclei are round and bland. No mitotic figures were seen; (C, D) tumor cells were diffusely positive for S100 and glial fibrillary acidic protein (GFAP).

Table 1 Immunohistochemistry staining results

\begin{tabular}{|c|l|c|}
\hline Stain & Results & Characteristics \\
\hline S100 & Positive & \\
\hline Neu-N & Positive & Weak \\
\hline GFAP & Positive & Diffuse \\
\hline Synaptophysin & Positive & \\
\hline EMA & Positive & Focal \\
\hline CD68 & Positive & Macrophages \\
\hline BRAF & Positive & Focal \\
\hline Ki67 & Positive & $<5 \%$ \\
\hline Mutant IDH1 & Negative & \\
\hline
\end{tabular}

Abbreviations: S100, S100 protein; BRAF, BRAF mutation test; CD68, GFAP, glial fibrillary acid protein; Ki67, Ki-67 labeing index.

consider that his condition of total disability and full dependency ( $40 \%$ on KPS scale) has positively changed to a functional status, in which he is able to care for most of his needs (60\% on KPS scale) and can be included in a rehabilitation program.

\section{Discussion}

The DLGNT, also known as disseminated oligodendrogliallike leptomeningeal tumor of childhood, is a primary CNS tumor characterized by diffuse leptomeningeal dissemination of neoplastic glioneuronal cells. Despite its indolent progression, it can rarely present itself as an isolated parenchymal lesion, and the morbidity and mortality rates are frequently high. ${ }^{4,5}$ Sometimes, its behavior can be more aggressive, especially in adults or elderly people. ${ }^{2}$ The clinical manifestations are directly related to the development of hydrocephalus and infiltration of spinal and cranial nerves.

On MRI, the DLGNT is characteristically described as thick, nodular leptomeningeal enhancement particularly around the basal cisterns, which may extend over the surface of the brain and spinal cord. Further findings are the presence of small subpial cysts or nodular T2 hyperintense lesions. Usually, it is isointense on T1-weighted images and exhibits remarkable contrast enhancement, typically located in the posterior fossa, brainstem, spinal cord, and cauda equine. ${ }^{3,4,6}$ One of the most important characteristics of the DLGNT is that, often, there is no definitely dominant primary parenchymal mass, even though, in the descriptions of some cases, 


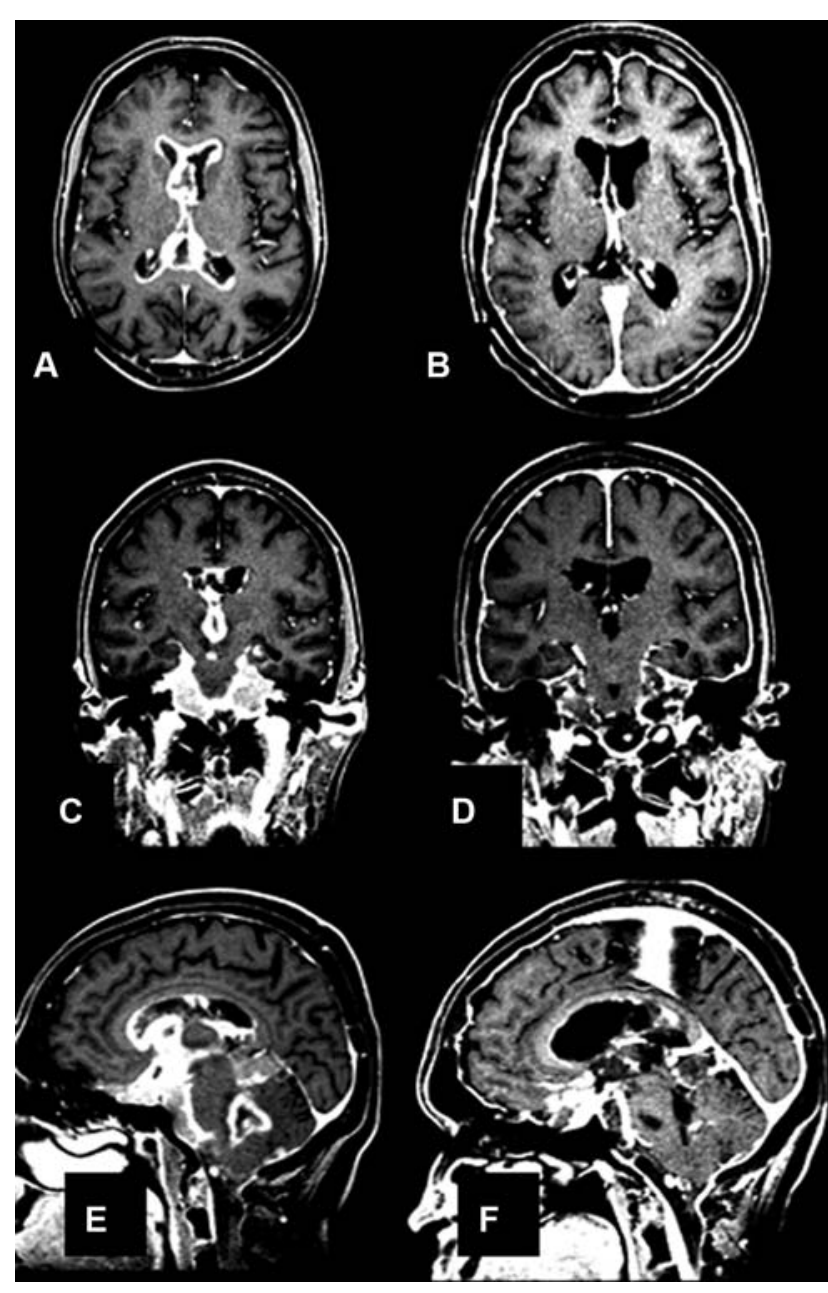

Fig. 4 T1-weighted magnetic resonance imaging with gadolinium pre and posttreatment. Partial remission of the tumor in response to radiotherapy plus procarbazine, lomustine, and vincristine (PCV) chemotherapy. The nodular and thick gadolinium enhancement observed on pretreatment T1-weighted magnetic resonance imaging ( $A, C$ and $E$ ) became thinner and less intense 3 months after the treatment (B, D and F).

intraparenchymal lesions were detected, more frequently in the spinal cords. ${ }^{3,4}$ In the initial stages, the radiographic diagnosis might be challenging, since an idiopathic communicating hydrocephalus and an unspecific diffuse leptomeningeal contrast enhancement of the basal cisterns and spinal cord might represent several diseases. The main differential diagnoses to DLGNT are tuberculous meningitis, meningeal carcinomatosis from primary or secondary neoplasms, and fungal meningitis. ${ }^{5}$

The histogenesis of DLGNT is unknown, but it is postulated that they originate from multipotent cells, positive for glial and neuronal markers, which are capable of divergent differentiation. ${ }^{4}$ In the histological aspect, these tumors have a low to moderate cellularity with a biphasic astrocytic population (positive for glial fibrillary acidic protein [GFAP]) and neurocytes (positive for synaptophysin). The monomorphic aspect is predominant and consists of oligodendroglial-like cells with clear cytoplasm and rounded nuclei. The DLGNT usually has low mitotic rate. The pres- ence of anaplasia or Ki67 $>4 \%$ might predict a worse prognosis. The main immunohistochemical findings are: high reactivity to oligodendrocyte transcription factor 2 (OLG-2), microtubule-associated protein 2 (MAP-2) and S100. Typically, the NeuN, EMA, and mutant IDH1 (R132H) are negative. ${ }^{4}$

All DLGNT carry chromosomal arm 1p deletion, as others genetic and epigenetics aberrations that are believed to activate the mitogen-activated protein kinase/ extracellular-signal-regulated kinase (MAPK/ERK) pathway, mostly because of the KIAA1549: BRAF fusion. Such changes have been proposed as tumors biomarkers and therapeutic targets, but there is currently a lack of evidence that mitogenactivated protein kinase (MEK) inhibitors may improve the clinical outcome of patients with DLGNT. ${ }^{3}$

Diffuse leptomeningeal glioneuronal tumor can be subdivided in two molecular classes, based on DNA methylation profiling, namely, DLGNT-MC- 1 and DLGNT-MC-2. ${ }^{3}$ It is supposed that codeletion $1 \mathrm{p} 19 \mathrm{q}$ is much more frequent in the DLGNT-MC-1 group, which is associated to a lower age of diagnosis (median 5 vs 14 years) and a less aggressive clinical course. Furthermore, all patients in the DLGNT-MC-2 group display a gain of chromosome $1 \mathrm{p}$ arm.

There is no guideline to treat DLGNT, and the current approaches are based on low-grade glioma's treatment of children and young adults. It is not clear if different combinations of surgery, radiotherapy, and chemotherapy can improve the clinical outcomes and survival; therefore, a conservative or palliative approach must not be ruled out. Promising outcomes have been described with temozolomide, bevacizumab, and vincristine associated with carboplatin, and the E-HIT 2000-4 and SIOP-LGG 2004 chemotherapy protocols. ${ }^{4,5}$

In conclusion, our case report suggests that radiotherapy plus PCV chemotherapy can have positive effects on DLGNT treatment and should be considered as a good approach to treat this particular tumor.

\section{Compliance with Ethical Standards}

The present case report has not been previously presented or published in part or in full.

The present case report has been written in accordance with Committee on Publication Ethics (COPE) guidelines and complies with the Case Report (CARE) guidelines.

\section{Patient Consent}

The patient has agreed with the present case report article and has consented to its submission to the journal.

Conflict of Interests

The authors declare that there is no conflict of interests.

\section{References}

1 Deng MY, Sill M, Chiang J, et al. Molecularly defined diffuse leptomeningeal glioneuronal tumor (DLGNT) comprises two subgroups with distinct clinical and genetic features. Acta Neuropathol 2018;136(02):239-253 Doi: 10.1007/s00401-018-1865-4 
2 Fiaschi P, Badaloni F, Cagetti B, et al. Disseminated oligodendroglial-like leptomeningeal tumor in the adult: Case Report and Review of the Literature. World Neurosurg 2018;114:53-57Doi: 10.1016/jj.wneu.2018.02.160

3 Gardiman MP, Fassan M, Orvieto E, et al. Diffuse leptomeningeal glioneuronal tumors: a new entity? Brain Pathol 2010;20(02): 361-366Doi: 10.1111/j.1750-3639.2009.00285.x

4 Lee J, Ko H, Choi J, et al. A Case of Diffuse Leptomeningeal Glioneuronal Tumor Misdiagnosed as Chronic Tuberculous Meningitis without Brain Biopsy. Case Rep Neuol Med 2018

5 Louis DN, Perry A, Reifenberger G, et al. The 2016 World Health Organization Classification of Tumors of the Central Nervous
System: a summary. Acta Neuropathol 2016;131(06):803-820Doi: 10.1007/s00401-016-1545-1

6 Peerboccus M, Beltran-Marin M, Sariban E, Fontanges Q Ziereisen F. Disseminated Oligodendroglial-like Leptomeningeal Tumor of Childhood: A Distinctive Entity Revised and Correlated with Pathology. J Belg Soc Radiol 2017;101(01):19Doi: 10.5334/jbrbtr.1012

7 Preuss M, Christiansen H, Merkenschlager A, et al. Disseminated oligodendroglial-like leptomeningeal tumors: preliminary diagnostic and therapeutic results for a novel tumor entity [corrected]. J Neurooncol 2015;124(01):65-74Doi: 10.1007/s11060015-1735-z 